\title{
A EDUCAÇÃO PROFISSIONAL NA REDE ESTADUAL DO RIO GRANDE DO NORTE: EM BUSCA DA CONSOLIDAÇÃO
}

\author{
J. M. N. DA SILVA ${ }^{1}$, S. M. N. DO NASCIMENTO ${ }^{2}$, M. DA C. P. RAMOS ${ }^{3}$ \\ Instituto Federal de Educação, Ciência e Tecnologia do Rio Grande do Norte ${ }^{1,2}$, Faculdade de Economia do Porto ${ }^{3}$ \\ ORCID ID: http://orcid.org/0000-0002-2799-6835 \\ jmns2008@hotmail.com ${ }^{1}$
}

DOI: $10.15628 /$ holos.2020.10053

\section{RESUMO}

A temática deste estudo é a educação profissional. O objetivo é desvelar os avanços promovidos pela Rede Estadual de Educação do Rio Grande do Norte a fim de expandir e consolidar essa oferta educacional. Metodologicamente, trata-se de uma abordagem qualitativa, subsidiada por pesquisa bibliográfica, apoiando-se em autores tais como Kuenzer (2009), Manfredi (2002), Nascimento (2019) e Silva, K. (2017), entre outros, e pesquisa documental (Leis, decretos e resoluções). Aborda-se os aspectos históricos da educação profissional na Rede Estadual de Educação do Rio Grande do Norte, a fim de situar as ações governamentais para essa modalidade, e o Programa Brasil Profissionalizado (PBP) na Rede Estadual de
Educação do Rio Grande do Norte, como indutor da expansão e consolidação dessa oferta. Os resultados apontam que, historicamente, as ações governamentais nesse campo epistêmico foram tímidas e acompanharam o movimento do Governo Federal, tanto em relação ao tipo de oferta dos cursos técnicos quanto a sua desobrigação, em consonância com a legislação; que o PBP contribuiu decisivamente para a retomada e expansão da educação profissional na Rede Estadual de Educação do Rio Grande Norte; e que o governo do Estado vem envidando esforços para a sua consolidação.

PALAVRAS-CHAVE: Educação profissional, Rede Estadual de Educação do Rio Grande do Norte, Programa Brasil Profissionalizado.

\section{PROFESSIONAL EDUCATION IN THE RIO GRANDE DO NORTE STATE NETWORK: IN SEARCH OF CONSOLIDATION}

\begin{abstract}
The theme of this study is professional education. The objective is to reveal the advances promoted by the State Education Network of Rio Grande do Norte in order to expand and consolidate this educational offer. Methodologically, it is a qualitative approach, supported by bibliographical research, based on authors such as Kuenzer (2009), Manfredi (2002), Nascimento (2019) and Silva, K. (2017), among others, and documentary research (Laws, decrees and resolutions). We focus on the historical aspects of professional education in the State Education Network of Rio Grande do Norte, in order to locate the government actions for this modality, and the Brazil Professionalized Program (PBP) in the State
\end{abstract}

Education Network of Rio Grande do Norte, as an inducer of the expansion and consolidation of this offer. The results indicate that, historically, governmental actions in this epistemic field have been timid and have followed the movement of the Federal Government, both in relation to the type of offer of technical courses as well as their disengagement, accordingly to the legislation; that the PBP contributed decisively to the resumption and expansion of professional education in the State Education Network of Rio Grande Norte, and that the State government has been making efforts to consolidate it.

KEYWORDS: Professional education, State Education Network of Rio Grande do Norte, Brazil Professional Program. 


\section{INTRODUÇÃO}

A educação profissional no Brasil vem se conformando de acordo com as concepções de sociedade e trabalho implantados no país, de modo que, de uma perspectiva assistencialista, destinada aos escravos, índios e órfãos, nos tempos da Colônia e do Império, e aos desvalidos da sorte na primeira República, passou à qualificação de operários vocacionais na década de 1930, à formação de profissionais para a indústria e o comércio, sob a égide das leis orgânicas dos anos 1940, de técnicos de nível médio para subsidiar os modelos nacional-desenvolvimentistas das décadas de 1960 e 1970, ao cidadão produtivo na década de 1990 e à formação mais completa de trabalhadores por meio da vinculação da formação técnica a uma sólida base científica, nos anos 2000.

O regime federativo da República brasileira possibilitou aos governos estaduais criarem as suas próprias redes de ensino profissional ${ }^{1}$. Tanto que o Estado de São Paulo, em 1892, criou cursos noturnos para menores trabalhadores e, em 1911, começaram a funcionar as primeiras escolas profissionais oficiais; e o Estado do Rio de Janeiro, em 1906, fundou três escolas de ofícios. (Manfredi, 2002).

No Estado do Rio Grande do Norte, a primeira ação governamental no campo da educação profissional ocorreu em 1922, com a criação da Escola Profissional do Alecrim, que funcionava em um anexo às dependências do Grupo Escolar Frei Miguelinho, localizado no bairro homônimo.

Daí resulta o objetivo nesse estudo, decorrido quase um século dessa primeira ação, que é desvelar os avanços promovidos pelos sucessivos governos, a fim de materializar a oferta da educação profissional na Rede Estadual de Educação do Rio Grande do Norte.

Metodologicamente, o estudo se enquadra em uma abordagem qualitativa, sustentada por pesquisas bibliográfica e documental. A abordagem qualitativa diz respeito a um conjunto de práticas materiais e interpretativas mobilizadas pelo pesquisador quando em contato com a situação estudada, a fim de entender, descrever ou explicar os fenômenos em termos dos sentidos que as pessoas Ihes atribuem. (Denzin \& Lincoln, 2006).

A pesquisa bibliográfica é aquela desenvolvida a partir de material já publicado, constituído principalmente de livros, artigos científicos, dissertações e teses, e se propõe à análise das diversas posições dos autores acerca de determinado assunto (Gil, 2008); nesse estudo apoiou-se em autores tais como Kuenzer (2009), Manfredi (2002), Nascimento (2019) e Silva, K. (2017), entre

\footnotetext{
${ }^{1}$ O próprio Governo Federal instituiu, também, sua própria rede de ensino profissional. Em 1909, o então Presidente Nilo Peçanha, por meio do Decreto no 5.766, de 23 de setembro, criou 19 Escolas de Aprendizes Artífices, destinadas ao ensino profissional primário. Ao longo de um século, essas Escolas se transformaram em Liceus Industriais, Escolas Técnicas Federais, Centros Federais de Educação Tecnológica e, a partir de 2008, em Institutos Federais de Educação.
}

HOLOS, Ano 36, v.4, e10053, 2020 
outros. A pesquisa documental, se baseia em materiais que ainda não receberam um tratamento analítico, tais como documentos oficiais (leis, decretos, resoluções, portarias, etc.), relatórios, jornais e revistas (Gil, 2008); utilizou-se, para tanto, a Lei de Diretrizes e Bases da Educação Nacional de 1996, o Plano Estadual de Educação do Rio Grande do Norte (2015-2025) e o Sistema Integrado de Gestão da Educação (SIGEDUC), da Secretaria de Estado da Educação Rio Grande do Norte, entre outros.

O presente estudo está organizado em duas partes, além da Introdução e das Considerações Finais. Na primeira parte, trata-se dos aspectos históricos da educação profissional na Rede Estadual de Educação do Rio Grande do Norte, a fim de situar as ações governamentais para essa modalidade. E, na segunda, o Programa Brasil Profissionalizado na Rede Estadual de Educação do Rio Grande do Norte, como indutor da expansão e consolidação dessa oferta.

\section{ASPECTOS HISTÓRICOS DA EDUCAÇÃO PROFISSIONAL NA REDE ESTADUAL DE EDUCAÇÃO DO RIO GRANDE DO NORTE}

Na Rede Estadual de Educação do Rio Grande do Norte, a história da educação profissional teve início na década de 1920, no governo de Antônio José de Mello e Souza (1920-1923), com a criação da Escola Profissional do Alecrim, anexa ao Grupo Escolar ${ }^{2}$ Frei Miguelinho, que oferecia os cursos de serralharia, marcenaria e sapataria e tinha por finalidade promover a aprendizagem de um ofício às crianças de 10 a 13 anos.

De acordo com M. Silva (2014), na época da Primeira República, a economia potiguar se sustentava por atividades agropecuárias e extrativistas, com destaque para a pecuária bovina, a cotonicultura, a canavieira e a extração do sal marinho e da scheelita, para o autoconsumo e para exportação. No entanto, no que diz respeito ao ensino profissional, a proposição era, assim como o Governo Federal o fez, educar as crianças excluídas socialmente (desvalidas, pobres, ociosas), para o trabalho, retirando-as da rua.

A ampliação da escolarização primária, segundo K. Silva (2017), foi um marco no governo de Juvenal Lamartine (1928-1930). Em 1929, foi criado um curso profissional feminino de artes manuais, anexo ao Grupo Escolar Duque de Caxias, no município de Macau, e tantos outros na capital do Estado, como os vinculados aos Grupos Escolares Izabel Gondim e João Tibúrcio, tanto que, em 1930, havia 588 alunos matriculados nas escolas profissionais, dos quais 92 estavam matriculados na Escola Profissional do Alecrim.

\footnotetext{
2 Segundo K. Silva (2017), o ensino primário no Rio Grande do Norte, à época, era materializado por meio de grupos escolares e escolas isoladas. O primeiro - Grupo Escolar Augusto Severo -, foi criado em março de 1908, no governo de Alberto Frederico de Albuquerque Maranhão (1908-1913). Grupo escolar era a reunião de três ou mais escolas isoladas agrupadas segundo a proximidade entre elas.
}

HOLOS, Ano 36, v.4, e10053, 2020 
Essa expansão no número de matrículas, pode-se inferir, decorre do fato de que a década de 1930 marcou, no Brasil, o fim da economia baseada no modelo agrário-exportador, sustentado pela cafeicultura, e o início do processo de industrialização, baseado no fortalecimento do setor de bens de produção.

O modelo econômico nacional-desenvolvimentista do governo Getúlio Vargas (1930-1945), de valorização do mercado interno, mediante a adoção de medidas de caráter mais protecionistas, favoreceu à industrialização, apoiada pelo processo de substituição de importações ${ }^{3}$ - produzindo no país o que antes era importado -, e pelas multinacionais que se instalaram no país. Isso exigiu a instituição de um conjunto de políticas públicas relativas, entre outras, à reformulação do aparelho estatal, a regulamentação das relações trabalhistas e a qualificação dos trabalhadores de acordo com as especificidades de cada região brasileira.

Na década de 1940, a Reforma Capanema, de ideologia nacionalista, trouxe nova organicidade para a educação nacional, mediante as Leis Orgânicas: do Ensino Secundário (1942), do Ensino Industrial (1943), do Ensino Comercial (1943) e do Ensino Primário (1946), do Ensino Normal (1946) e do Ensino Agrícola (1946). Paralelamente, foram criados o Senai (1942) e o Senac (1946), visando à formação de profissionais para a indústria e o comércio, respectivamente.

A reforma do ensino industrial - Decreto-lei n. 4.078/1942 - teve como fundamento a transferência do ensino profissional primário para o ensino secundário. O ensino industrial foi estruturado em dois ciclos: o primeiro, com os cursos industriais básicos, ofertados nas escolas industriais para formar artífices e, o segundo, com os cursos técnicos, nas escolas técnicas, para a formação de técnicos especializados.

O estudo de K. Silva (2017) revela que, em 1944, o Estado do Rio Grande do Norte era administrado por Antônio Fernandes Dantas (1943-1945), que criou 186 escolas isoladas. Em seu governo o ensino profissional foi ressaltado pela Escola Profissional do Alecrim e pela Escola Feminina de Comércio de Natal, criada em 1939. No final da década, já no governo de José Augusto Varela (1947-1951), foi criada, por meio da Lei no 202 de dezembro de 1949, a Escola Agrícola de Jundiaí ${ }^{4}$ no município de Macaíba, com a oferta dos cursos de agricultura e zootecnia, para a formação de equipes de técnicos indispensáveis ao exercício dessas profissões.

No início da década de 1950, no governo de Sylvio Pedrosa (1951-1956), o ensino profissional, na Rede Estadual do Estado do Rio Grande do Norte, contava com 33 cursos de

\footnotetext{
${ }^{3}$ Este processo, proposto pela Comissão Econômica para a América Latina e o Caribe (CEPAL) como um dos esforços necessários à redução da dependência dos países latino-americanos aos países industrializados, vigorou, no Brasil, até meados da década de 1960.

${ }^{4}$ Em 1967, por força do Decreto no 61.162, de 16 de agosto, foi incorporada à Universidade Federal do Rio Grande do Norte. Em 2007 passou à condição de Unidade Acadêmica Especializada em Ciências Agrárias, integrada à estrutura acadêmica e administrativa da UFRN. Atualmente, oferta cursos de formação tecnológica de nível médio, de graduação e de pós-graduação nessa área de conhecimento.
}

HOLOS, Ano 36, v.4, e10053, 2020 
iniciação profissional e com 667 alunos matriculados. A Escola Profissional Feminina oferecia, em 1951, os cursos de Corte e Costura, Artes Culinárias, Datilografia e Prendas Domésticas; a Escola Profissional do Alecrim, continuava a ofertar os cursos de Sapataria, Artes Gráficas, Serralheria, Alfaiataria e Marcenaria; e a Escola Agrícola de Jundiaí os cursos acima mencionados. (K. Silva, 2017).

É importante ressaltar que, no governo Kubitschek (1956-1961) a indústria brasileira inaugurou um novo período de crescimento, devido ao desenvolvimento do setor de bens de consumo duráveis (automóveis, eletrodomésticos e similares) e a abertura da economia ao capital estrangeiro, com todos os estímulos e benefícios do Estado, tal como os recebidos pelas grandes montadoras, como a Volkswagen, a Mercedes-Benz, a General Motores e a Ford as quais se estabeleceram no país. (Mendonça, 2004). Paralelamente, fomentou a oferta de cursos técnicos nas escolas industriais e escolas técnicas mantidas pela União, a fim de intensificar a formação de pessoal técnico especializado para subsidiar as demandas da expansão industrial brasileira.

A partir da década de 1960 até meados da de 1980, o Brasil experimentou o Regime CivilMilitar. Instaurado em 1964, os diversos governos militares que se sucederam nesse período buscaram consolidar o modelo econômico desenvolvimentista implantado em meados da década anterior. Associados ao capital internacional (a quem ofereceu inúmeras vantagens), optaram pela estratégia de desenvolvimento voltada para os grandes projetos nacionais: construção de polos petroquímicos, hidrelétricas e grandes rodovias, como a transamazônica. (Manfredi, 2002).

Nesse período, o país viveu a mais estreita relação entre educação e trabalho, uma vez que a firme preocupação da Ditadura Civil-Militar era compatibilizar a política educacional com os princípios da grande indústria capitalista (no caso brasileiro, do modelo de produção tayloristafordista), com vistas a aumentar a produtividade desta. Assim, estabeleceu, por meio da reforma do Ensino de 1을 e 2 o Graus - Lei n. 5.692/1971 -, o ensino profissionalizante para todos, objetivando formar quadros técnicos para imediata inserção no mercado de trabalho.

Especificamente, a referida Lei organizou a educação básica da seguinte forma: i) ensino de 10 grau, aglutinando o ensino primário e o ginasial, com oito anos de duração e obrigatório, dos 7 aos 14 anos; e ii) o ensino de 2 o grau, profissionalizante, constituído pelos cursos colegiais (secundário, técnico e normal), com três ou quatro anos de duração. (Lei n. 5.692, 1971).

Com isso, segundo J. Silva (2014), essa Lei propiciou a elevação da escolarização mínima da classe trabalhadora, por extinguir o exame de admissão obrigatório ao curso ginasial existente e buscou promover a generalização do ensino profissionalizante, mediante a obrigatoriedade de habilitações técnicas para todos no $2^{\circ}$ grau, para atender às necessidades do mercado de trabalho.

É importante destacar que o 2 o grau profissionalizante foi concebido sobre os princípios tecnicistas os quais pregavam a racionalidade, eficiência e produtividade, ou seja, direcionada 
unicamente para o adestramento do estudante - futuro trabalhador -, preparando-o para execução de tarefas técnicas, sem a pretensão da oferta de uma formação mais ampla e crítica.

De acordo com Carlos (2018), na década de 1970, sob a égide da Lei n. 5.692/1971, a Rede Estadual de Educação do Rio Grande do Norte manteve ações tímidas no âmbito da educação profissional. Existiam apenas 21 escolas ofertantes de ensino técnico profissionalizante, a maioria na capital do Estado. Já nos anos 1980, o ensino de 20 grau tomou corpo no Estado, mediante a sua oferta em 103 escolas, e na primeira metade da década de 1990, apenas 42 escolas com essa oferta educacional. Mas não estavam presentes em todos os municípios do Estado, só em 113 dos 167 municípios.

Ainda segundo essa autora, entre as décadas de 1970 e 1990, a Rede Estadual de Educação do Rio Grande do Norte ofertou 38 habilitações técnicas no ensino de 2o grau, entre as quais: Magistério, Assistente Administrativo, Auxiliar de Administração, Auxiliar de Escritório, Auxiliar de Contabilidade, Técnico de Contabilidade, Secretariado Executivo, Auxiliar de Crédito e Finanças, Auxiliar de Enfermagem, Auxiliar de Prótese Dentária, Técnico em Edificações, Técnico em Agropecuária, Técnico em Mecânica, ou seja, a predominância era de cursos vinculados ao setor terciário da economia. (Carlos, 2018).

Inferimos que a concentração da oferta de cursos profissionalizantes no setor terciário deve-se ao fato de que a Rede Estadual de Educação do Rio Grande do Norte precisava cumprir a Lei n. 5.692/1971, mas não dispunha das condições materiais (laboratórios, oficinas, equipamentos, acervo bibliográfico, materiais para aulas práticas e professores especializados) para a oferta de cursos na área industrial, e aqueles cursos demandavam o mínimo de investimento possível.

Em suma, no período do Regime Civil-Militar, houve uma ampliação na oferta do ensino profissionalizante de 2 o grau na Rede Estadual de Educação do Rio Grande do Norte, em consequência do número de habilitações e de escolas ofertantes. Todavia, com o advento da Lei n. 7.044/1982, que revogou a obrigatoriedade da profissionalização no 2o grau, o Estado do Rio Grande do Norte, a exemplo de tantos outros Estados da Federação, iniciou a oferta de cursos de 2o grau não profissionalizantes em 93 escolas e, ao mesmo tempo, reduziu drasticamente a oferta dos cursos técnicos, de modo que, com a aprovação da Lei de Diretrizes e Bases da Educação Nacional de 1996 (LDB/1996) essa última oferta praticamente foi extinta no Estado.

Na segunda metade da década de 1990, a LDB/1996, reorganizou a educação do país em dois níveis: educação básica (constituída pela educação infantil, ensino fundamental e ensino médio) e educação superior; estabeleceu cinco modalidades de educação, entre as quais a educação profissional, a qual seria desenvolvida em articulação com os diferentes níveis e as outras modalidades, ou por diferentes estratégias de educação continuada, tendo como finalidade 
possibilitar ao educando o permanente desenvolvimento de aptidões para a vida produtiva. (Lei $n$. 9.394, 1996).

Em abril de 1997, o governo Fernando Henrique Cardoso (1995-2002) publicou o Decreto n. 2.208 que organizou a educação profissional em três níveis: a) básico (para qualificação, requalificação e reprofissionalização de trabalhadores); b) técnico (com organização curricular própria e independente do ensino médio, podendo ser oferecido de forma concomitante ou sequencial a esse); e c) tecnológico (cursos de nível superior na área tecnológica). (Decreto $\mathrm{n}$. $2.208,1997)$.

Ou seja, literalmente, estabeleceu a separação formal entre os ensinos médio e técnico, de modo que aquela etapa teria como finalidade a formação propedêutica, com foco no prosseguimento de estudos, e essa modalidade, ajustada às necessidades do mercado do trabalho, para o desenvolvimento de aptidões para a vida produtiva.

Como consequência das mudanças introduzidas pela LDB/1996 e pelo Decreto $\mathrm{n}$. 2.208/1997, a Rede Estadual de Educação do Rio Grande do Norte arrefeceu ainda mais a oferta de cursos técnicos, passando a ofertar apenas cursos de ensino médio propedêutico. No entanto, no ano 2000, na gestão do governador Garibaldi Alves Filho (1995-2002), foi firmado o Convênio n. 281/2000, com a Secretaria de Educação Profissional e Tecnológica (SETEC), do Ministério da Educação (MEC), por meio do Programa de Expansão da Educação Profissional (PROEP) ${ }^{5}$, para a estruturação do Centro Estadual de Educação Profissional Senador Jessé Pinto Freire (CENEP) ${ }^{6}$, a primeira unidade escolar específica para a formação profissional na Rede Estadual de Educação. (Mororó, 2018).

Em 2002, o Conselho Estadual de Educação, por meio da Resolução de n. 02/2002-CEE/RN, normatizou a educação profissional estadual. Essa Resolução, apoiada no Decreto n. 2.208/1997, estabeleceu que, na Rede Estadual de Educação do Rio Grande do Norte, a educação profissional em nível técnico poderia ser desenvolvida na forma concomitante ou sequencial, com os seguintes objetivos: promover a transição entre a escola e o mundo do trabalho, habilitando jovens e adultos com conhecimentos gerais e específicos a fim de aplicá-los em sua vida social e produtiva; formar profissionais de nível médio aptos a aplicar os conhecimentos adquiridos em atividades gerais e específicas; e especializar, atualizar e aperfeiçoar o trabalhador em seus conhecimentos científicos e tecnológicos. (Nascimento, 2019).

\footnotetext{
${ }^{5}$ Esse Programa foi instituído pelo MEC, em parceria com o Ministério do Trabalho e Emprego (MTE) e o Banco Interamericano de Desenvolvimento (BID), em novembro de 1997, para subsidiar a implantação da reforma da educação profissional promovida pelo governo Fernando Henrique Cardoso.

${ }^{6}$ O CENEP foi oficialmente criado em 2002, no governo de Fernando Antônio da Câmara Freire (2002-2003), por meio do Decreto Estadual no 16.592, de 18 de dezembro.
}

HOLOS, Ano 36, v.4, e10053, 2020 
Ou seja, a intenção era promover uma educação profissional vinculada à perspectiva técnica e economicista - ao modelo de produção taylorista-fordista, com a segregação entre o saber e o fazer -, com foco na preparação para inserção no mercado do trabalho, em detrimento de uma formação mais completa, que possibilitasse ao educando sua inclusão política, social, cultural, laboral etc.

Em 2006, quatro anos após sua criação, o CENEP teve suas atividades educacionais iniciadas, mediante a oferta dos cursos técnicos de Manutenção e Suporte em Informática e de Gestão Empresarial, na forma subsequente, e, no ano seguinte, também na forma de ensino médio integrado e integrado à educação de jovens e adultos, esse último, por meio do Programa Nacional de Integração da Educação Profissional com a Educação Básica na Modalidade de Jovens e Adultos (PROEJA). (Mororó, 2018; Nascimento, 2019).

Ainda em 2006, o governo de Wilma Maria de Faria (2003-2010) firmou convênio com o MEC para a implantação de um projeto piloto de educação profissional integrada ao ensino médio nas seguintes Escolas Estaduais: Francisco Ivo, Edgar Barbosa e José Fernandes Machado, em Natal; Prof. Abel Freire Coelho, em Mossoró; e José Fernandes de Melo, em Pau dos Ferros. Essa experiência teve início em 2008 e vida curta - em 2012, essas escolas descontinuaram essa oferta -, ficando apenas o CENEP como única unidade escolar ofertante de educação profissional na Rede Estadual de Educação do Rio Grande do Norte. (Nascimento, 2019).

Assim, a história da educação profissional na Rede Estadual de Educação do Rio Grande do Norte revela que as ações governamentais nesse campo epistêmico foram tímidas e acompanharam o movimento do Governo Federal, tanto em relação ao tipo de oferta dos cursos técnicos quanto a sua desobrigação, em consonância com a legislação. Ou seja, não percebemos, em todo o período estudado, a intenção de qualquer governo no sentido de se firmar essa oferta educacional no âmbito estadual.

Todavia, desde 2008, a Rede Estadual de Educação do Rio Grande do Norte participa do Programa Brasil Profissionalizado, cuja implementação só teve início em 2017. Daí a necessidade de nos debruçarmos sobre esse Programa, para apreender as possibilidades que ele traz como indutor da expansão e da consolidação da educação profissional na Rede Estadual, tema a ser abordado na próxima seção.

\section{O PROGRAMA BRASIL PROFISSIONAL NA REDE ESTADUAL DE EDUCAÇÃO DO RIO GRANDE DO NORTE: RUMO À CONSOLIDAÇÃO}

Na primeira década dos anos 2000, o governo Lula da Silva (2003-2010) promoveu uma nova organização à educação profissional no país, por meio do Decreto n. 5.154/2004, possibilitando a reintegração dos ensinos médio e técnico, e instituiu uma série de Programas focais nessa modalidade de educação, tais como o Projeto Escola de Fábrica, em 2005, o Programa HOLOS, Ano 36, v.4, e10053, 2020 
Nacional de Integração da Educação Profissional com a Educação Básica na Modalidade de Educação de Jovens e Adultos (PROEJA), em 2006, o Programa Brasil Profissionalizado (PBP), em 2007 e o Programa Nacional de Inclusão de Jovens (Projovem), em 2008. Ademais, desenvolveu, a partir de 2005, o Plano de Expansão para a Rede Federal de Educação Profissional e Tecnológica, construindo e instalando 214 novas unidades de ensino em todo o território nacional e, em 2008, criou os Institutos Federais de Educação. (J. Silva, 2014).

De acordo com o Decreto n. 5.154 (2004) - que revogou o Decreto n. 2.208/1997 e foi incorporado à LDB/1996, pela Lei n. 11.741/2008 -, a educação profissional passou a ser desenvolvida por meio de cursos e programas de: a) formação inicial e continuada de trabalhadores; b) educação profissional técnica de nível médio (nas formas integrada, concomitante ou subsequente); e c) educação profissional tecnológica de graduação e de pósgraduação.

O Programa Brasil Profissionalizado (PBP) foi instituído pelo Decreto n. 6.302 (2007), no âmbito do MEC, com a finalidade de estimular, nas redes estaduais de educação ${ }^{7}$, o ensino médio integrado à educação profissional, enfatizando a educação científica e humanística, por meio da articulação entre formação geral e educação profissional no contexto dos arranjos produtivos e das vocações locais e regionais.

Para tanto, o Programa objetiva, entre outros aspectos: a) desenvolver e reestruturar o ensino médio, de forma a combinar formação geral, científica e cultural com a formação profissional dos educandos; b) propiciar a articulação entre a escola e os arranjos produtivos locais e regionais; e c) fomentar a expansão da oferta de matrículas no ensino médio integrado à educação profissional, pela rede pública de educação dos Estados, do Distrito Federal e dos Municípios, inclusive na modalidade a distância. (Decreto n. 6.302, 2007).

De fato, esses objetivos evidenciam a tentativa do governo federal em promover a integração do ensino médio com a educação profissional nas redes estaduais de educação, através da oferta de cursos técnicos integrados condizentes com os arranjos produtivos locais e regionais e, em consequência, fomentar a expansão das matrículas.

A assistência financeira ${ }^{8}$ às ações (construção, reformas ou ampliações dos espaços físicos escolares, aquisição de acervo bibliográfico e mobiliário, desenvolvimento de gestão e formação de professores) para a consecução da finalidade do Programa nos estados e municípios, se materializou mediante a celebração de convênios entre esses entes federados e o MEC/Fundo

\footnotetext{
7 Conforme preceitua a LDB/1996, as redes estaduais de educação, oferecem, prioritariamente, o ensino médio propedêutico, isto é, um curso de formação geral cujo objetivo é preparar o estudante para prosseguimento dos estudos no ensino superior.

${ }^{8}$ A meta inicialmente prevista pelo MEC/FNDE era investir R\$ 900 milhões entre 2008 e 2011 . No entanto, segundo Relatórios de Gestão elaborados pela SETEC/MEC, no período foram investidos R\$ 1,9 bilhão (mais do que o dobro da meta inicial), atendendo 24 das 27 unidades da Federação.
}

HOLOS, Ano 36, v.4, e10053, 2020 
Nacional de Desenvolvimento da Educação (FNDE). A contrapartida dos estados e municípios era a infraestrutura de obras, manutenção do funcionamento das escolas e a criação e/ou adequação do quadro docente, sobretudo das disciplinas específicas da educação profissional. (Resolução n. 062, 2007).

Em 2008, o governo do Estado aderiu ao PBP mediante a celebração de dois convênios (e outros dois em 2009), sendo contemplado com R\$124,1 milhões; a contrapartida do governo foi da ordem de 1\% (R\$ 1,2 milhão). As ações previstas foram ampliar e/ou reformar 109 escolas de ensino médio que passariam a ofertar educação profissional; adquirir equipamentos para três núcleos de educação a distância; adquirir acervo bibliográfico e equipamentos para a composição de laboratórios técnicos e científicos; realizar três seminários para a formação dos profissionais que atuariam nessas escolas; e construir 10 Centros Estaduais de Educação Profissional (CEEP). (Nascimento, 2019).

Nesse sentido, concordamos com Kuenzer (2009, p. 45), quando afirma que "A melhoria das condições de sucesso e permanência dos estudantes depende de uma série de investimentos, tendo em vista a qualidade de ensino: em equipamentos, em ampliação do espaço físico, na qualificação permanente dos professores." Ou seja, os investimentos delineados pelo governo estadual assertivamente conduzem à ampliação da oferta da educação profissional na Rede Estadual e, consequentemente, à elevação do número de matrículas nessa modalidade.

O governo estadual executou as ações previstas, no todo ou em parte: das 109 escolas que receberiam reformas e/ou ampliação, 53 foram concluídas, das quais 51 - Quadro 1 - iniciaram ofertas de cursos técnicos a partir de 2017; dos 10 CEEP, 8 - Quadro 2 - foram concluídos e estão em funcionamento desde $2017^{9}$ (os três restantes estão, ainda, em fase final de conclusão); os equipamentos, mobiliários, laboratórios e acervo bibliográfico adquiridos foram distribuídos entre as 53 escolas e os 7 CEEP; e os três seminários programados, para o desenvolvimento da gestão e da formação dos profissionais que atuariam nas escolas foram realizados. (Nascimento, 2019).

\footnotetext{
${ }^{9}$ Antes da oferta de cursos técnicos pelas escolas e CEEP mencionados, o governo estadual aderiu, em 2011, ao Programa Nacional de Acesso ao Ensino Técnico e ao Emprego (PRONATEC) - instituído no governo Dilma Rousseff (2011-2016), pela Lei no 12.513, de 26/10/2011, com a finalidade de ampliar a oferta de educação profissional e tecnológica, prioritariamente, a estudantes do ensino médio da rede pública, trabalhadores e beneficiários dos programas federais de transferência de renda. (BRASIL, 2011) -, como Instituição Demandante, com o objetivo de garantir a oferta de educação profissional para os alunos da Rede Estadual de Educação. Para tanto, estabeleceu parceria com as Instituições Ofertantes (Instituto Federal de Educação, do Rio Grande do Norte (IFRN); Universidade Federal do Rio Grande do Norte (UFRN); Escola Agrícola de Jundiaí (EAJ); Escola de Enfermagem; Escola de Música; e Sistema "S"), através das quais, ofertou cursos nas dependências de 11 escolas reformadas, nas modalidades Formação Inicial e Continuada (FIC) e Técnico Concomitante, entre 2011 e 2013, beneficiando 31.856 estudantes no período. Todavia, as matrículas não puderam ser computadas como da Rede Estadual de Educação, uma vez que a Instituição Ofertante e, não a Demandante, é que registram como suas as matrículas.
} 
Quadro 1: Escolas Estaduais do Rio Grande do Norte beneficiadas pelo PBP.

\begin{tabular}{|c|c|c|c|}
\hline \# & MUNICÍPIO & ESCOLA ESTADUAL & CURSOS TÉCNICOS INTEGRADOS \\
\hline 1 & Natal & Des. Floriano Cavalcanti & Administração \\
\hline 2 & Natal & Gov. Walfredo Gurgel & Energia Renovável \\
\hline 3 & Natal & Prof. Luís Antônio & Segurança do Trabalho \\
\hline 4 & Natal & Prof. José Fernandes Machado & Administração \\
\hline 5 & Natal & Berilo Wanderley & Informática \\
\hline 6 & Canguaretama & Guiomar Vasconcelos & Segurança do Trabalho \\
\hline 7 & Goianinha & Prof. João Tibúrcio & Segurança do Trabalho \\
\hline 8 & Parnamirim & Dr. Antônio de Souza & Administração \\
\hline 9 & São José do Mipibu & Prof. Francisco Barbosa & Administração \\
\hline 10 & Brejinho & José Lúcio Ribeiro & Segurança do Trabalho \\
\hline 11 & Nova Cruz & Rosa Pignataro & Manutenção e Suporte em Informática \\
\hline 12 & Passagem & Prof. Antônio Fagundes & Administração \\
\hline 13 & Bom Jesus & José Alves de Melo & Informática \\
\hline 14 & Ielmo Marinho & lelmo Marinho & Segurança do Trabalho \\
\hline 15 & Pendências & Prof. Honório Amorim & Manutenção e Suporte em Informática \\
\hline 16 & Coronel Ezequiel & José Joaquim & Manutenção e Suporte em Informática \\
\hline 17 & Santa Cruz & João Ferreira de Souza & Administração \\
\hline 18 & Santa Cruz & José Bezerra Cavalcante & Guia de Turismo \\
\hline 19 & Sítio Novo & José Nunes de Carvalho & Guia de Turismo \\
\hline 20 & Afonso Bezerra & Profa Gildecina Bezerra & Agroecologia \\
\hline 21 & Lajes & Pedro II & Edificações \\
\hline 22 & Pedro Avelino & Profa Josefa Sampaio Marinho & Manutenção e Suporte em Informática \\
\hline 23 & Cerro Corá & Querubina Silveira & Informática \\
\hline 24 & Currais Novos & Manoel Salustino & Mineração \\
\hline 25 & Florânia & Teônia Amaral & Segurança do Trabalho \\
\hline 26 & Parelhas & Prof. Amâncio Ramalho & Manutenção e Suporte em Informática \\
\hline 27 & São Vicente & Aristófanes Fernandes & Informática \\
\hline 28 & Caicó & José Augusto & Manutenção e Suporte em Informática \\
\hline 29 & Caicó & Calpúrnia Caldas de Amorim & Edificações \\
\hline 30 & Jardim do Seridó & Centro Educacional Felinto Elísio & Manutenção e Suporte em Informática \\
\hline 31 & Jucurutu & Newmam Queiroz & Segurança do Trabalho \\
\hline 32 & Serra Negra do Norte & Prof. Leomar Batista & Informática \\
\hline 33 & Ouro Branco & Manoel Correia & Informática \\
\hline 34 & Açu & Juscelino Kubitschek & Manutenção e Suporte em Informática \\
\hline 35 & Mossoró & José de Freitas Nobre & Informática \\
\hline 36 & Mossoró & Prof. José Nogueira & Nutrição e Dietética \\
\hline 37 & Mossoró & Jerônimo Rosado & Sistema de Energia Renovável \\
\hline 38 & Mossoró & Prof. Abel Freire Coelho & Informática \\
\hline 39 & Serra do Mel & José de Anchieta & Informática \\
\hline 40 & Upanema & José Calazans Freire & Manutenção e Suporte em Informática \\
\hline 41 & Tibau & Rui Barbosa & Informática \\
\hline 42 & Apodi & Profa Maria Zenilda Gama Torres & Informática \\
\hline 43 & Apodi & Prof. Antônio Dantas & Edificações \\
\hline 44 & Apodi & Valdemiro Pedro Viana & Administração \\
\hline 45 & Caraúbas & Lourenço Gurgel & Administração \\
\hline 46 & Itaú & Francisco de Assis Pinheiro & Manutenção e Suporte em Informática \\
\hline 47 & Severiano Melo & Severiano Melo & Administração \\
\hline
\end{tabular}

HOLOS, Ano 36, v.4, e10053, 2020 


\begin{tabular}{|l|l|l|l|}
\hline 48 & Almino Afonso & Estudante Ronald Neo Junior & Manutenção e Suporte em Informática \\
\hline 49 & Frutuoso Gomes & Ivonete Carlos & Informática \\
\hline 50 & Major Sales & 26 de Junho & Edificações \\
\hline 51 & São Francisco do Oeste & Prof. Manoel Herculano & Segurança do Trabalho \\
\hline 52 & Parazinho & Senador Jessé Pinto Freire* & Agroecologia \\
\hline 53 & Jandaíra & $\begin{array}{l}\text { Prof.a Maria da Conceição } \\
\text { Messias* }\end{array}$ & Administração \\
\hline 54 & São Bento do Norte & Senador Dinarte Mariz* & Manutenção e Suporte em Informática \\
\hline
\end{tabular}

Fonte: Nascimento (2019).

$(*)$ Essas três escolas não foram contempladas com recursos do PBP, mas ofertaram cursos técnicos.

Quadro 2. Centros Estaduais de Educação Profissional do Rio Grande do Norte.

\begin{tabular}{|c|c|c|}
\hline CEEP & MUNICÍPIO & CURSOS TÉCNICOS INTEGRADOS \\
\hline \multirow{2}{*}{ Prof. João Faustino Ferreira Neto } & \multirow{2}{*}{ Natal } & Meio Ambiente \\
\hline & & Nutrição \\
\hline \multirow{2}{*}{ Profa Dijanira Brasilino de Souza } & \multirow{2}{*}{ Natal } & Administração \\
\hline & & Meio Ambiente \\
\hline \multirow{2}{*}{ Hélio Xavier de Vasconcelos } & \multirow{2}{*}{ Extremoz } & Administração \\
\hline & & Recursos Humanos \\
\hline \multirow{2}{*}{ Dr. Ruy Pereira dos Santos } & \multirow{2}{*}{$\begin{array}{l}\text { São Gonçalo do } \\
\text { Amarante }\end{array}$} & Edificações \\
\hline & & Segurança do Trabalho \\
\hline \multirow{2}{*}{ Prof. Lourdinha Guerra } & \multirow{2}{*}{ Parnamirim } & Informática \\
\hline & & Manutenção e Suporte em Informática \\
\hline \multirow{2}{*}{ Ruy Antunes Pereira } & \multirow{2}{*}{ Ceará-Mirim } & Sistemas de Energia Renováveis \\
\hline & & Administração \\
\hline \multirow{2}{*}{ Prof. Maria Rodrigues Gonçalves } & \multirow{2}{*}{ Alto do Rodrigues } & Informática \\
\hline & & Sistemas de Energia Renováveis \\
\hline \multirow{2}{*}{ Prof. Francisco de Assis Pedrosa } & \multirow{2}{*}{ Mossoró } & Meio Ambiente \\
\hline & & Nutrição e Dietética \\
\hline
\end{tabular}

Fonte: Silva e Nascimento (2019).

Com efeito, a Rede Estadual de Educação do Rio Grande do Norte registrou, em 2017, um total de 3.116 matrículas no âmbito da educação profissional, representando um aumento de 348,35\% em relação ao total do ano anterior (695 matrículas); em 2018 e em 2019, foram computadas 5.136 e 7.057 matrículas, respectivamente. (Sistema Integrado de Gestão da Educação [SIGEDUC], 2020).

A referida ampliação no número de matrículas ratifica o que Viana (2017, p. 149) afirma: "A expansão das vagas das redes estaduais de educação profissional, nos últimos anos, mostra que, desde a implementação do PBP, houve aumento significativo no número de vagas oferecidas por essas redes, saltando de 253.194 vagas, em 2007, para 488.543, em 2012."

Assim, podemos inferir que o PBP contribuiu decisivamente para a retomada e expansão da educação profissional na Rede Estadual de Educação do Rio Grande Norte e, dessa forma, oportuniza aos estudantes potiguares, por um lado, sua formação ou qualificação para (re)inserção no mundo do trabalho e, por outro, seu desenvolvimento pessoal, social, político e cultural, que o permite conduzir seu projeto de vida. 
Para além da motivação econômica - a educação profissional é condicionada às necessidades de qualificação para o mercado de trabalho e como estratégica para o desenvolvimento econômico - e, perseguindo, de um lado, a qualidade e a consolidação da educação profissional na Rede Estadual de Educação do Rio Grande do Norte e, de outro, o alcance das metas estabelecidas no Plano Estadual de Educação ${ }^{10}$ - Lei n. 10.049, de 27.01.2016 - o governo do Estado vem realizando esforços para equipar as escolas que ofertam cursos técnicos com laboratórios e equipamentos os quais darão suporte às aulas práticas; garantir a contratação de professores para as áreas técnicas específicas; promover política de formação continuada de gestores e professores que atuam nessas unidades; e ampliar as possibilidades de oferta tanto de cursos técnicos de nível médio quanto de formação inicial e continuada.

As ações concorrem, assim, para a formação mais ampla dos estudantes, não apenas possibilitando conhecimentos para ter acesso ao mundo do trabalho (a uma ocupação formal, informal, intermitente ou esporádica remunerada), ou a uma gestão empreendedora (disposição para criar e desenvolver o seu próprio negócio, e oferecer um produto ou serviço de interesse da sociedade), como também para a elevação de escolaridade (verticalizando o ensino com curso superior e de pós-graduação) e para o exercício social, político e cultural consciente dos potiguares.

\section{CONSIDERAÇÕES FINAIS}

Historicamente, a educação profissional no Brasil e, particularmente, na Rede Estadual de Educação do Rio Grande do Norte, tem a marca da descontinuidade, uma vez que a cada sucessão de governo, programas são instituídos com base em releitura das ações governamentais anteriormente promovidas.

A trajetória da educação profissional na Rede Estadual de Educação do Rio Grande do Norte revela ações tímidas nesse campo epistêmico. Inicialmente, com a oferta de ensino profissional (cursos de serralharia, marcenaria e sapataria) nos anos 1920, para as crianças de 10 a 13 anos; depois, de uma forma mais alargada nas décadas de 1970 e 1980, por meio das habilitações técnicas, conforme previstas na reforma do ensino de 1 으 e 2 ㅇ graus, no período da Ditadura CivilMilitar, que estabeleceu a profissionalização universal e compulsória no ensino de 2 o grau; em seguida, sua quase extinção na década de 1990; depois, a criação do CENEP e da experiência piloto com algumas escolas na primeira década dos anos 2000; e, enfim, a retomada com uma significativa expansão a partir de 2017, motivadas pelo PBP.

De modo geral podemos inferir que o PBP cumpriu sua finalidade e objetivos estabelecidos, uma vez que as ações para a retomada, modernização e expansão da educação profissional na

\footnotetext{
${ }^{10}$ A Meta 2, da Dimensão 3 - Educação e Trabalho: formação técnica de nível médio e tecnológica, prevê "triplicar as matrículas da Educação Profissional Técnica de Nível Médio, assegurando a qualidade da oferta, com pelo menos $50 \%$ (cinquenta por cento) da expansão no segmento público." (Lei n. 10.049, 2016, p. 19).
}

HOLOS, Ano 36, v.4, e10053, 2020 
Rede Estadual de Educação do Rio Grande do Norte se materializaram, contribuindo para uma formação profissional e cidadã dos estudantes.

A reforma e/ou ampliação de 53 escolas de ensino médio possibilitaram a oferta de cursos técnicos e a construção de 10 CEEP, além da aquisição de equipamentos, mobiliários e acervo bibliográfico para todas elas, além da realização de formação continuada para gestores e professores dessas unidades, por meio do PBP, permitiu à Rede Estadual de Educação Norte-riograndense viabilizar a retomada e a expansão da educação profissional na Rede, ainda que tenha enfrentado dificuldades materiais (ausência de laboratórios para aulas práticas) e de pessoal (professores técnicos especializados das disciplinas específicas dos cursos) para a sua implementação.

O aumento das matrículas entre 2017 e 2019 apontam para a perspectiva da consolidação dessa oferta educacional na Rede Estadual. Para tanto, o governo do Estado vem desenvolvendo esforços para dotar as unidades escolares dos equipamentos, mobiliários e laboratórios, bem como para construir um quadro de professores, nomeadamente das áreas técnicas, o que resultará, decisivamente, na aprendizagem e desenvolvimento dos estudantes potiguares.

\section{REFERÊNCIAS}

Carlos, N. L. S. D. (2018). 0 ensino de 20 Grau no Estado do Rio Grande do Norte: uma história da implantação da Lei no 5.692/1971 (1971-1996) (Dissertação de mestrado). Programa de PósGraduação em Educação Profissional, Instituto Federal de Educação, Ciência e Tecnologia do Rio Grande do Norte, Natal, Brasil.

Decreto n. 2.208, de 17 de abril de 1997 (1997). Regulamenta o § 2 do art. 36 e os arts. 39 a 42 da Lei $n$ ㅇ 9.394, de 20 de dezembro de 1996, que estabelece as diretrizes e bases da educação nacional. Brasília, DF: Presidência da República. Recuperado em 02 junho 2017, de http://www.planalto.gov.br/ccivil_03/decreto/D2208.htmimpressa.htm.

Decreto n. 6.302, de 12 de dezembro de 2007 (2007). Institui o Programa Brasil Profissionalizado. Brasília, DF: Presidência da República. Recuperado em 02 junho 2017, de http://www.planalto.gov.br/ccivil_03/_Ato2007-2010/2007/Decreto/D6302.htm.

Denzin, N. K. \& Lincoln, Y. S. (2006). O planejamento da pesquisa qualitativa: teorias e abordagens. Porto Alegre: Bookman, Artmed.

Gil, A. C. (2008). Métodos e técnicas de pesquisa social (6a ed.). São Paulo: Atlas.

Kuenzer, A. Z. (Org.) (2009). Ensino médio: construindo uma proposta para os que vivem do trabalho (6a ed.). São Paulo: Cortez.

Lei n. 5.692, de 11 de agosto de 1971 (1971). Fixa diretrizes e bases para o ensino de $1^{\circ}$ e $2 \circ$ graus, e dá outras providências. Brasília, DF: Presidência da República. Recuperado em 13 junho 2009, de http://www.planalto.gov.br/ccivil_03/Leis/L5692.htm. 
Lei n. 9.394, de 20 de dezembro de 1996 (1996). Estabelece as diretrizes e bases da educação nacional. Brasília, DF: Presidência da República. Recuperado em 05 abril 2012, de https://www.planalto.gov.br/ccivil_03/Leis/L9394.htm.

Lei n. 12.513, de 26 de outubro de 2011 (2011). Institui o Programa Nacional de Acesso ao Ensino Técnico e Emprego (Pronatec) e dá outras providências. Brasília, DF: Presidência da República. Recuperado em 20 agosto 2017, de https://www.planalto.gov.br/ccivil_03/_ato20112014/2011/lei/l12513.htm.

Lei n. 10.049, de 27 de janeiro de 2016 (2016). Aprova o Plano Estadual de Educação do Rio Grande do Norte (2015-2025) e dá outras providencias. Natal, RN: Governo do Estado do Rio Grande do Norte. Recuperado em 20 agosto 2017, de http://simec.mec.gov.br/sase/sase_mapas.php?acao=downloadEstado\&estuf=RN\#: :text=G RANDE\%20DO\%20NORTE-

,LEI\%20N\%C2\%BA\%2010.049\%2C\%20DE\%2027\%20DE\%20JANEIRO\%20DE\%202016.,DO\%20R IO\%20GRANDE\%20DO\%20NORTE\%3A\&text=8\%C2\%BA\%20da\%20Lei\%20Federal\%20n\%C2\% BA,(PNE\%202014\%2D2024)..

Manfredi, S. M. Educação profissional no Brasil. São Paulo: Cortez, 2002.

Mendonça, S. R. (2004). A industrialização brasileira (2a ed.). São Paulo: Moderna.

Mororó, D. C. S. (2018). Tecnologias da informação e comunicação nas práticas docentes no Proeja do Centro Estadual de Educação Profissional Senador Jessé Pinto Freire (CENEP): limites e possibilidades para formação humana integral (Dissertação de mestrado). Programa de Pós-Graduação em Educação Profissional, Instituto Federal de Educação, Ciência e Tecnologia do Rio Grande do Norte, Natal, Brasil.

Nascimento, S. M. N. (2019). Os Centros Estaduais de Educação Profissional no Rio Grande do Norte: desafios e possibilidades (Dissertação de mestrado). Programa de Pós-Graduação em Educação Profissional, Instituto Federal de Educação, Ciência e Tecnologia do Rio Grande do Norte, Natal, Brasil.

Resolução n. 062, de 12 de dezembro de 2007 (2007). Estabelece as diretrizes para a assistência financeira a Estados, Distrito Federal e Municípios no âmbito do Programa Brasil Profissionalizado. Brasília, DF: Fundo Nacional de Desenvolvimento da Educação. Disponível em: http://www.diariodasleis.com.br/busca/exibelink.php?numlink=1-164-34-2007-12-1262. Acesso em: 05/06/2017.

Silva, J. M. N. (2014). Concepções de formação profissional técnica de nível médio adotadas pelo IFRN: especificidades e (des)continuidades (Tese de doutorado). Programa de Pós-Graduação em Educação, Universidade Federal do Rio Grande do Norte, Natal, Brasil.

Silva, J. M. N., \& Nascimento, S. M. N. (2019). Os Centros Estaduais de Educação no Rio Grande do Norte: ampliando o horizonte do ensino técnico no Estado. In NUNES, A. O., SOUZA, F. C. S., \& PONTES, V. M. A. (Org.). Ensino na Educação Básica. V. III (pp. 296-312). Natal: IFRN. 
Silva, K. K. O. (2017). $O$ ensino profissional do Rio Grande do Norte: indícios da ação do estado de 1908 a 1957 (Dissertação de mestrado). Programa de Pós-Graduação em Educação Profissional, Instituto Federal de Educação, Ciência e Tecnologia do Rio Grande do Norte, Natal, Brasil.

Silva, M. G. (2014). Dinâmica econômica recente e reestruturação produtiva no Rio Grande do Norte (1970-2000). História econômica \& história de empresas. São Paulo, 17 (1), 257-294.

Sistema Integrado de Gestão da Educação (SIGEDUC), 2020. Acompanhamento da educação, relatório sintético de turmas. Natal, RN: Secretaria de Estado da Educação Rio Grande do Norte. Recuperado em 21 abril 2020, de https://sigeduc.rn.gov.br/sigeduc/verTeçaLpgin.do.

VIANA, C. F. M. (2017). Programa Brasil Profissionalizado: coordenação federativa, formulação e implementação da política nacional de expansão das redes estaduais de educação profissional. Perspectivas em Políticas Públicas, Belo Horizonte, X (19), 129-163.

\section{COMO CITAR ESTE ARTIGO:}

Silva, J.M.N, Nascimento, S.M.N, Ramos, M.C.P. (2020). A Educação Profissional na Rede Estadual do Rio Grande do Norte: em busca da consolidação. Holos, 36(4), 1-17.

\section{SOBRE OS AUTORES}

\section{JOSÉ MOISÉS NUNES DA SILVA}

Doutor em Educação pela Universidade Federal do Rio Grande do Norte (UFRN); Professor do Programa de Pós-Graduação em Educação Profissional (PPGEP), do Instituto Federal de Educação, Ciência e Tecnologia do Rio Grande do Norte (IFRN). E-mail: jmns2008@hotmail.com

ORCID ID: http://orcid.org/0000-0002-2799-6835

\section{SUERDA MARIA NOGUEIRA DO NASCIMENTO}

Mestre em Educação pelo Programa de Pós-Graduação em Educação Profissional (PPGEP), do Instituto Federal de Educação, Ciência e Tecnologia do Rio Grande do Norte (IFRN). E-mail: suerda.mnascimento@gmail.com

ORCID ID: http://orcid.org/0000-0003-0415-8836

\section{MARIA DA CONCEIÇÃO PEREIRA RAMOS}

Doutora em Ciência Económica - Economia dos Recursos Humanos, pela Universidade de Paris I, Sorbonne. Professora de Economia, da Faculdade de Economia do Porto, Portugal. E-mail: cramos@fep.up.pt ORCID ID: http://orcid.org/0000-0003-4173-5428

Editor(a) Responsável: Francinaide de Lima Silva Nascimento Pareceristas Ad Hoc: Amailson Barros e Antonio Uchoa 


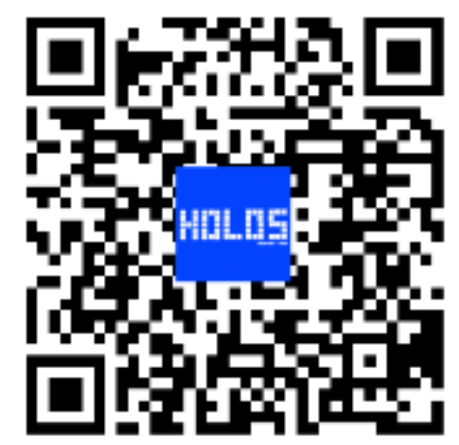

Recebido: 05 de maio de 2020

Aceito: 17 de junho de 2020

Publicado: 01 de julho de 2020 